\title{
Tissue culture capacities of different explants from China elite common wheat and their correlation analysis
}

\author{
Jie Gao', Fengzhi Guo ${ }^{2}$, Yu lian Li ${ }^{1}$, Qingqi Fan', Peng Meng1, Shuimei Liang', \\ Chengyan Huang ${ }^{1}$, Xiusheng $\mathrm{Chu}^{1}$ and Genying $\mathrm{Li}^{1}{ }^{1 *}$
}

\begin{abstract}
${ }^{1}$ Crop Research Institute, Shandong Academy of Agricultural Sciences/Key Laboratory of Wheat Biology and Genetic Improvement On North Yellow and Huai River Valley, Ministry of Agriculture P.R China/National Engineering Laboratory For Wheat and Maize, Jinan 250100.

${ }^{2}$ Crop Research Institute, Heze Academy of Agricultural Sciences, Heze, Shandong, 274000, China.
\end{abstract}

Accepted 30 July, 2012

\begin{abstract}
To screen out cultivars with excellent tissue culture capacities for genetic transformation, the callus induction and regeneration response of immature embryos, inflorescences and anthers from 50 China new released cultivars with excellent agronomic performance were evaluated. The results showed that, among the surveyed cultivars, the callus induction frequency of immature embryos and inflorescences were genotype-independent. Whereas, the regeneration frequency of callus induced from immature embryos were significantly different, with less than $60 \%$, from 60 to $80 \%$ and more than $90 \%$ in 36 , eight and six cultivars, respectively. The regeneration frequency of the induced callus from inflorescences differed significantly, with less than $60 \%$, from 40 to $90 \%$ and more than $90 \%$ in 34,11 and five cultivars, respectively. However, both the callus induction and green plantlets regeneration frequencies of anthers were significant different among the cultivars, with the induction frequency less than $25 \%$, from 25 to $60 \%$, and more than $75 \%$ in 33,14 and three cultivars, respectively. The green plantlets regeneration frequency of the callus induced from anthers ranged from 42.5 to $88.5 \%$ in different cultivars. Tissue culture capacities of immature embryos and inflorescences were highly correlated. Whereas, both of them have low correlations with anther culture capacity.
\end{abstract}

Key words: Common wheat, inflorescences, immature embryos, isolated anthers, tissue culture capacity.

\section{INTRODUCTION}

Common wheat is one of the most important food resources. The sustainable and sufficient wheat supply plays critical roles in food security. The continuous increasing population requires more and more wheat production, conflicting with the declining and deteriorating land and water resources. To solve this problem, the only way is to harvest more from the limited arable land. However, due to the limited available germplasm and the changeable climates, conventional breeding is facing a bottleneck on how to increase the yield. Genetic engineering makes it possible to introduce the alien genes to wheat chromosome and create new germplasm with excellent agronomic traits, which was vital in varieties breeding. Thus, genetic engineering was considered as one of the most important technologies to break through the bottleneck (Bhalla et al., 2006). 
Previous studies showed that the callus induction and regeneration system is the major one used in wheat transformation, and tissue culture capacities of different explants had great effects on transformation efficiency (Pellegrineshi et al., 2002). To date, various explants such as immature embryos (Barro et al., 1999; Fennell et al., 1996; Wu et al., 2009), inflorescences (Caswell et al., 2000; Kavas et al., 2008; Maddock et al.,1983), isolated anthers (Brisbe et al., 2000; Soriano et al., 2008), isolated microspores (Mejza et al., 1993; Liu et al., 2004), mature embryos (Wang et al., 2009; Patnaik et al., 2006; Özgen et al., 1998, 2001), and shoot tips (Haliloglu et al., 2006; Viertel et al., 1996), leaf base (Wang et al., 2004) were successfully used for tissue culture, and immature embryos, 14 days after pollination with the size about 1.0 $\mathrm{mm}$, were the most common explants used for transformation.

The transformation efficiency was much more depended on the callus induction and regeneration frequency, which were quite different among cultivars with different genetic backgrounds (Zale et al., 2004; Maddock et al., 1983; Raziuddin et al., 2010; Sharma et al., 1995). Therefore, it is very important to select an ideal cultivar as recipient. Bobwhite is a very nice cultivar used worldwide for genetic transformation ( $\mathrm{Hu}$ et al., 2003; Cheng et al., 1997), while Yangmai 158 and Xinchun 9 are also excellent cultivars in immature embryo culture and they have been successfully used for producing transformants in China (Ye et al., 2005; Zhang et al., 2007, 2009), but all the aforementioned cultivars are spring wheat, and it takes long time to transfer the integrated alien genes into winter wheat by several generations backcrosses. Therefore, to accelerate the breeding progress, donor plants used for genetic transformation should not only have excellent tissue culture capacity but also desirable agronomic traits.

So, it is a promising pathway to directly introduce the alien genes into current released wheat cultivars or advanced lines with winter growth habit. Among the four wheat growing regions in China, Huang-Huai wheat region is the largest one with the largest production and largest sowing area, accounting for $70 \%$ of China wheat production (He et al., 2001; Zhuang et al., 2003). Only the cultivars with winter growth habit can survive the winter freezing temperature in this region. Thus, lots of transformation works make use of winter wheat as the donor plants in China (Ding et al., 2009; Zhang et al., 2009). Shandong which is the second largest wheat production area in China, release cultivars with excellent agronomic traits every year, these cultivars have broad adaptations in Huang-Huai wheat region. To understand the tissue culture capacity of these genotypes, immature embryos, inflorescences and anthers isolated from 50 cultivars released in 2009 were cultured on their corresponding medium, the callus induction and regeneration ability of those explants were evaluated, and the relationships of tissue culture capacity among different explants were first reported in the present study, which provided very useful information in explants and cultivars selection during genetic transformation.

\section{MATERIALS AND METHODS}

A total of 50 cultivars with excellent agronomic traits, released in 2009, were selected from the Wheat Germplasm Bank of Shandong Academy of Agricultural Science, and planted in an irrigated experimental field located in Jinan, in 2009 to 2010 cropping season according to local management practices. Spikes from main tiller were harvested at 14th days after pollination (DAP). The isolated seeds were washed with $70 \%$ ethanol for $30 \mathrm{~s}$ and sterilized in $1 \%$ hypochlorous acid for $10 \mathrm{~min}$. Immature embryos with the exact size of $1 \pm 0.1 \mathrm{~mm}$ were incubated on the SD2 induction medium: Murashige and Skoog (MS) (1962) salts supplement with thiamine $1 \mathrm{mg} / \mathrm{L}$, glutamine $150 \mathrm{mg} / \mathrm{L}, 2,4$ dichlorophenoxyacetic acid (2,4-D) $2 \mathrm{mg} / \mathrm{L}$, sucrose $3 \%$, agar $0.7 \%$, $\mathrm{pH} 5.8$, keep in dark at $25^{\circ} \mathrm{C}$, and four days later the axis was removed completely with the sharp scalpel under microscope and placed the scutellum on the same induction medium. The callus were transferred to fresh-made medium every two weeks, and four weeks after incubation in dark at $25^{\circ} \mathrm{C}$, the induced callus were transferred to regeneration medium $1 / 2 \mathrm{MS}$ supplement with $2 \mathrm{mg} / \mathrm{L}$ trans-zeatin, incubated at $25^{\circ} \mathrm{C}$ under the light intensity 40 $\mu \mathrm{mol} / \mathrm{s} . \mathrm{m}^{2}$, with $16 \mathrm{~h}$ day/ $8 \mathrm{~h}$ night. The green shoot formation and the regenerated plantlets were scored on the 35th day after the regeneration. Inflorescences were isolated when its size reached 6 $\pm 1 \mathrm{~mm}$. Each one was cut into several pieces with the size about 2 $\mathrm{mm}$, then incubated on the W4 induction medium (Risacher et al., 2009): MS basal medium supplement with 2,4-D $2 \mathrm{mg} / \mathrm{L}$, glutamine $500 \mathrm{mg} / \mathrm{L}$, casein $100 \mathrm{mg} / \mathrm{L}$, sucrose $20 \mathrm{~g} / \mathrm{L}$, agarose $6 \mathrm{~g} / \mathrm{L}$, keep in dark at $25^{\circ} \mathrm{C}$ for five weeks and changed to the fresh-made medium every two weeks. Record the numbers of induced callus, and transfer induced callus to regeneration medium: MS without any hormone, incubated at $25^{\circ} \mathrm{C}$ under the light intensity $40 \mu \mathrm{mol} / \mathrm{s} . \mathrm{m}^{2}$, $16 \mathrm{~h}$ day $/ 8 \mathrm{~h}$ night, and the numbers of green plantlets regenerated were recorded and calculated on 35th day after being transferred to regeneration medium.

Due to more than one plantlets were generated from one callus in some cultivars, and in order to decrease the bias in the fertile ability assessment of the regenerated green plantlets, only one plantlets regenerated from each induced callus of immature embryos and inflorescences was further transferred to pots with KLASMAN compost, vernalization at $4^{\circ} \mathrm{C}$ in the low temperature growth room for 40 days, then transferred to another growth room until harvest and grew under $16^{\circ} \mathrm{C}$ day $/ 20^{\circ} \mathrm{C}$ night with the photoperiod $16 \mathrm{~h}$ day $/ 8 \mathrm{~h}$ night, $500 \mu \mathrm{mol} / \mathrm{s} . \mathrm{m}^{2}$ light intensity. The agronomic traits were observed during the whole growing period and the produced seeds from each plant were recorded individually. Anthers with the majority of microspores at the mid- to late-uninucleate stage were isolated and inoculated to $\mathrm{C} 17$ induction medium: MS salts supplement with glycine $2 \mathrm{mg} / \mathrm{L}$, nicotinic acid $0.5 \mathrm{mg} / \mathrm{L}$, thiamine hydrochloride $1 \mathrm{mg} / \mathrm{L}$, pyridoxine hydrochloride $0.5 \mathrm{mg} / \mathrm{L}$, D-biotin $1.5 \mathrm{mg} / \mathrm{L}$, kinetin $0.5 \mathrm{mg} / \mathrm{L}, 2,4-\mathrm{D} 2 \mathrm{mg} / \mathrm{L}$, sucrose $90 \mathrm{~g} / \mathrm{L}$, agar 7 $\mathrm{g} / \mathrm{L}, \mathrm{pH}$ 5.8. They were kept in dark for three days at $30^{\circ} \mathrm{C}$, and then incubated at $25^{\circ} \mathrm{C}$ for four weeks. The induced embryoids or callus were calculated under the microscope and transferred to regeneration medium: MS salts supplement with glycine $2 \mathrm{mg} / \mathrm{L}$, nicotinic acid $0.5 \mathrm{mg} / \mathrm{L}$, thiamine hydrochloride $1 \mathrm{mg} / \mathrm{L}$, pyridoxine hydrochloride $0.5 \mathrm{mg} / \mathrm{L}$, D-biotin $1.5 \mathrm{mg} / \mathrm{L}$, kinetin2 $\mathrm{mg} / \mathrm{L}$, indole -3butyric acid (IBA) $0.5 \mathrm{mg} / \mathrm{L}$, sucrose $30 \mathrm{~g}$, agar $7 \mathrm{~g} / \mathrm{L}$, pH 5.8, under the light intensity $40 \mu \mathrm{mol} / \mathrm{s} \cdot \mathrm{m}^{2}$, with $16 \mathrm{~h}$ day $/ 8 \mathrm{~h}$ night. The regeneration plantlets were scored once a week and the regeneration plantlets were calculated at the 35th day after being transferred to regeneration medium. Numbers of regenerated green 

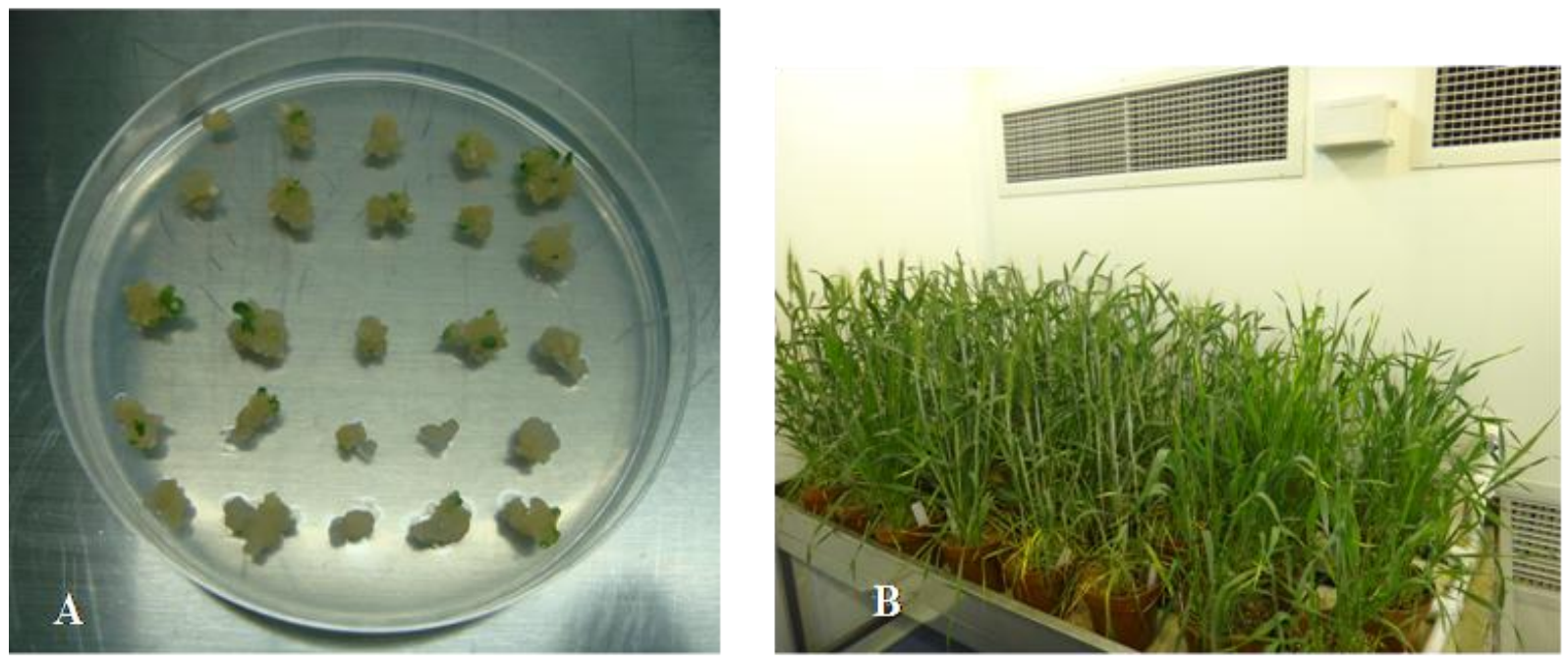

Figure 1. The callus induced from immature embyos and the agronomic performance of the regenerated plants. A. The callus induced from immature embyos after three weeks culture. B. The agronomic performance of the regenerated plantlets in growth room.

plantlets and albinos were calculated in four weeks.

One of the plantlets regenerated from each callus was further transferred to planting pots with KLASMAN compost, and vernalization at $4^{\circ} \mathrm{C}$ in the low temperature growth room for 40 days and then transferred to another growth room. With the occurrence of new tiller, the ploidy level of plantlets were analyzed by observing 10 stomatal guard cell length of each plant under the microscope at $400 \times$ magnification, following the method described by Sood et al.( 2003): Take out the haploids from compost and wash the root completely. Trim the roots and leaves to about $3 \mathrm{~cm}$, and put the trimmed plantlets into doubling solution (5\% dimethyl sulfoxide (DMSO), $0.2 \%$ cochicine) for $4 \mathrm{~h}$ with continuous aeration to the doubling solution. Together with the automatically doubled haploids, the treated haploids were washed thoroughly with fluid water for $5 \mathrm{~h}$ and re-planted to compost with $5 \mathrm{~g} / \mathrm{L}$ osmotic fertilizer, grew in the growth room under $16^{\circ} \mathrm{C}$ day $/ 20^{\circ} \mathrm{C}$ night with the photoperiod $16 \mathrm{~h}$ day $/ 8 \mathrm{~h}$ night, and $500 \mu \mathrm{mol} / \mathrm{s}^{\mathrm{m}} \mathrm{m}^{2}$ light intensity. The agronomic traits were observed during the whole growing period and the produced seeds from each plant were recorded individually.

In the aforementioned experiments, three replicates were made for each cultivar, and in each replicate, 30 immature embryos, 25 inflorescences and 100 anthers were isolated for tissue culture, respectively. Statistical analysis was performed using the Statistical Analysis System (SAS) software (SAS Institute Inc., Cary, NC, Version 9.1).

\section{RESULTS}

\section{The tissue culture capacity of immature embryos}

Five days after inoculation, globular stick up can be observed on the surface of scutellum under the microscope, the friable yellow-white embryonic structures appeared in some callus from different cultivars two weeks later, and the ratio of this structure in different cultivars are quite different. Some embryonic structure developed into green shoots on the induction medium in three weeks (Figure 1A). All of the embryos with the size of about $1 \mathrm{~mm}$ were developed into callus, so the induction ratio was $100 \%$ in all cultivars. The induced callus together with the developed shoots, were transferred to the regeneration medium four weeks after the axis removed. The regeneration frequency of the induced callus were significantly different at the level of $P<0.05$ (data not shown), with the regeneration frequency more than $90 \%$ in six cultivars, accounting for $10 \%$ of the surveyed cultivars, including three cultivars Yangmai158, Bobwhite, Liao0802 with a regeneration frequency of $100 \%$, respectively. While 36 cultivars had the regeneration frequency less than $60 \%$, accounting for $72 \%$, and the lowest two cultivars, SN09-30 and 034700, had the regeneration frequencies of 26.7 and $27.3 \%$, respectively (Table 1). Eight cultivars had the regeneration frequencies from 60 to $80 \%$, accounting for $16 \%$. After vernalization, the regenerated plantlets were transferred to the growth room, and 39 out the 50 surveyed cultivars obtained the matured seeds, while 11 cultivars had some plants with no pollen which cannot get seeds, and the ratios of the fertile plants in those cultivars were more than $96 \%$ (Table 1). The plantlets which cannot get the mature seeds were mainly dwarf mutants with no pollen. No obvious agronomic trait change was observed in fertile plantlets (Figure 1B).

\section{The tissue culture capacity of inflorescences}

The inflorescences with the length about $6 \mathrm{~mm}$ were isolated and cut into three pieces with the size about 2 $\mathrm{mm}$, and then inoculated to the induction medium. One week later, the initiated callus can be observed along the spike's edge, and three weeks later, the embryonic structures were visible with naked eyes (Figure 2A). Numbers of the induced callus were calculated on the 
Table 1. Tissue culture capacities of immature embryos, inflorescences and isolated anthers from different cultivars.

\begin{tabular}{|c|c|c|c|c|c|c|c|c|c|c|}
\hline Field entry & Cultivar & FRIM (\%) & FFIM (\%) & FRYS (\%) & FFYS (\%) & NCINAN & NRGP & FRGP (\%) & CANC (\%) & FFAN (\%) \\
\hline 1 & Luyuan185 & 51.3 & 98.7 & 45.3 & 100.0 & 16.3 & 12.3 & 75.5 & 12.3 & 86.5 \\
\hline 4 & Liao 0801 & 30.7 & 100.0 & 25.3 & 100.0 & 22.7 & 16.3 & 72.1 & 16.3 & 89.8 \\
\hline 8 & Lin 061 & 50.0 & 100.0 & 44.0 & 97.0 & 15.0 & 11.3 & 75.6 & 11.3 & 97.1 \\
\hline 11 & Luzi 0318-1 & 52.0 & 100.0 & 44.0 & 100.0 & 10.7 & 6.3 & 59.4 & 6.3 & 94.7 \\
\hline 12 & Liao 0802 & 100.0 & 98.7 & 97.3 & 100.0 & 12.3 & 7.7 & 62.2 & 7.7 & 91.3 \\
\hline 13 & 05428 & 31.3 & 100.0 & 29.3 & 100.0 & 15.3 & 9.0 & 58.7 & 9.0 & 96.3 \\
\hline 18 & Qifeng No.3 & 82.7 & 99.2 & 81.3 & 100.0 & 14.7 & 10.3 & 70.5 & 10.3 & 96.8 \\
\hline 19 & Tainong 7018 & 32.7 & 100.0 & 32.0 & 100.0 & 8.7 & 6.0 & 69.2 & 6.0 & 94.4 \\
\hline 25 & Wennong 18 & 96.0 & 100.0 & 97.3 & 97.3 & 22.0 & 14.3 & 65.2 & 14.3 & 95.4 \\
\hline 27 & Tainong 8681 & 83.3 & 99.2 & 80.0 & 100.0 & 18.0 & 15.0 & 83.3 & 15.0 & 95.6 \\
\hline 28 & SN055849 & 51.3 & 100.0 & 49.3 & 100.0 & 23.7 & 14.0 & 59.2 & 14.0 & 92.9 \\
\hline 31 & Wennong 19 & 30.0 & 100.0 & 36.0 & 100.0 & 20.0 & 11.3 & 56.7 & 11.3 & 91.2 \\
\hline 32 & Deyou 06-1 & 54.7 & 100.0 & 56.0 & 100.0 & 15.3 & 11.7 & 76.1 & 11.7 & 94.3 \\
\hline 34 & Tainong 8968 & 66.7 & 100.0 & 62.7 & 100.0 & 23.3 & 18.7 & 80.0 & 18.7 & 94.6 \\
\hline 35 & 055319 & 55.3 & 100.0 & 41.3 & 100.0 & 18.0 & 13.7 & 75.9 & 13.7 & 95.1 \\
\hline 37 & 9921 & 58.7 & 100.0 & 54.7 & 100.0 & 16.7 & 11.3 & 68.0 & 11.3 & 97.1 \\
\hline 38 & Shannong 06-205 & 34.0 & 100.0 & 36.0 & 100.0 & 13.7 & 12.0 & 87.8 & 12.0 & 97.2 \\
\hline 39 & Shannong 71 & 42.0 & 100.0 & 34.7 & 96.2 & 14.7 & 12.7 & 86.4 & 12.7 & 94.7 \\
\hline 43 & Shannong 044 & 65.3 & 100.0 & 70.7 & 94.3 & 14.7 & 12.0 & 81.8 & 12.0 & 91.7 \\
\hline 44 & Zhongzuo 155 & 46.0 & 100.0 & 46.7 & 100.0 & 32.7 & 24.3 & 74.5 & 24.3 & 86.3 \\
\hline 46 & 035373 & 83.3 & 99.2 & 81.3 & 100.0 & 26.3 & 16.7 & 63.3 & 16.7 & 92.0 \\
\hline 47 & Bpt06037 & 36.7 & 100.0 & 26.7 & 100.0 & 43.3 & 38.3 & 88.5 & 38.3 & 94.8 \\
\hline 51 & Heng 4399 & 85.3 & 99.2 & 81.3 & 100.0 & 28.7 & 21.3 & 74.4 & 21.3 & 96.9 \\
\hline 54 & 034700 & 27.3 & 100.0 & 28.0 & 100.0 & 28.0 & 17.0 & 60.7 & 17.0 & 90.2 \\
\hline 55 & 07PS22 & 91.3 & 100.0 & 86.7 & 96.9 & 33.0 & 17.3 & 52.5 & 17.3 & 92.3 \\
\hline 57 & 990512 & 74.7 & 100.0 & 66.7 & 100.0 & 33.3 & 24.7 & 74.0 & 24.7 & 98.7 \\
\hline 59 & By18 & 32.7 & 100.0 & 30.7 & 100.0 & 10.3 & 8.3 & 80.7 & 8.3 & 96.0 \\
\hline 61 & ВРТ0536 & 90.7 & 100.0 & 96.0 & 100.0 & 24.7 & 16.3 & 66.2 & 16.3 & 85.7 \\
\hline 62 & Shannong 05-0149 & 33.3 & 100.0 & 33.3 & 100.0 & 17.3 & 12.7 & 73.1 & 12.7 & 97.4 \\
\hline 67 & Zinong 0907 & 46.0 & 98.6 & 57.3 & 100.0 & 13.3 & 5.7 & 42.5 & 5.7 & 88.2 \\
\hline 69 & Kenxing No.1 & 48.0 & 100.0 & 25.3 & 100.0 & 10.3 & 7.0 & 67.7 & 7.0 & 90.5 \\
\hline 70 & SN09-30 & 26.7 & 100.0 & 33.3 & 100.0 & 9.0 & 7.3 & 81.5 & 7.3 & 90.9 \\
\hline 71 & 055318 & 46.0 & 100.0 & 50.7 & 97.4 & 12.7 & 10.0 & 79.0 & 10.0 & 96.7 \\
\hline
\end{tabular}

FRIM, Average frequency of immature embryos regeneration in three replicates; FFIM, average frequency of fertile plantlets regenerated from immature embryos; FRYS, average frequency of inflorescences regeneration in three replicates; FFYS, average frequency of fertile plantlets regenerated from young spikes; FCINAN, average callus induction frequency from isolated anthers in three replicates; NRGP, average numbers of regenerated green plantlets in three replicates; FRGP, average frequency of regenerated green plantlets in three replicates; ANCP, anther culture capacity; FFAN, average frequency of fertile plantlets regenerated from the induced callus of isolated anthers. 
Table 1. Continued.

\begin{tabular}{|c|c|c|c|c|c|c|c|c|c|c|}
\hline 73 & Shannong D919 & 85.3 & 100.0 & 93.3 & 100.0 & 25.3 & 18.3 & 72.4 & 18.3 & 87.3 \\
\hline 77 & SN738 & 40.0 & 100.0 & 25.3 & 100.0 & 55.7 & 46.0 & 82.6 & 46.0 & 95.7 \\
\hline 79 & Shannong 0801 & 36.7 & 100.0 & 34.7 & 100.0 & 42.3 & 33.3 & 78.7 & 33.3 & 96.0 \\
\hline 81 & Xingnong No.9 & 34.0 & 100.0 & 34.7 & 100.0 & 25.3 & 19.0 & 75.0 & 19.0 & 91.2 \\
\hline 82 & Dehan 06-3 & 32.0 & 97.9 & 65.3 & 100.0 & 33.0 & 27.3 & 82.8 & 27.3 & 97.6 \\
\hline 83 & Yangmai 158 & 100.0 & 98.7 & 96.0 & 98.6 & 24.7 & 14.7 & 59.5 & 14.7 & 93.2 \\
\hline 84 & K35 & 54.0 & 100.0 & 54.7 & 100.0 & 91.0 & 68.3 & 75.1 & 68.3 & 95.1 \\
\hline 85 & Ji8802 & 45.3 & 100.0 & 46.7 & 100.0 & 88.3 & 74.7 & 84.5 & 74.7 & 96.0 \\
\hline 86 & Weimai No.7 & 52.0 & 96.2 & 53.3 & 95.0 & 86.3 & 72.7 & 84.2 & 72.7 & 96.3 \\
\hline 87 & Jimai 20 & 40.0 & 100.0 & 36.0 & 100.0 & 15.7 & 12.3 & 78.7 & 12.3 & 91.9 \\
\hline 88 & Jimai 22 & 47.3 & 100.0 & 41.3 & 100.0 & 18.0 & 13.3 & 74.1 & 13.3 & 97.5 \\
\hline 89 & Yannong 19 & 46.7 & 100.0 & 48.0 & 100.0 & 32.7 & 23.3 & 71.4 & 23.3 & 92.9 \\
\hline 90 & Linmai No.4 & 58.0 & 100.0 & 65.3 & 95.9 & 36.7 & 25.7 & 70.0 & 25.7 & 93.5 \\
\hline 91 & Liangxing 99 & 34.7 & 100.0 & 38.7 & 100.0 & 19.7 & 14.7 & 74.6 & 14.7 & 93.2 \\
\hline 92 & Liangxing 66 & 36.7 & 100.0 & 46.7 & 100.0 & 21.3 & 12.7 & 59.4 & 12.7 & 94.7 \\
\hline 93 & Bobwhite & 100.0 & 99.3 & 88.0 & 100.0 & 24.7 & 15.3 & 62.2 & 15.3 & 93.5 \\
\hline 94 & Linmai No.6 & 46.0 & 100.0 & 40.0 & 96.7 & 14.0 & 8.0 & 57.1 & 8.0 & 83.3 \\
\hline
\end{tabular}

35th day, just before the callus was transferred to regeneration medium. The regenerated plantlets were induced in two weeks and stop to produce new plantlets after four weeks (Figure 2B). The statistical analysis indicated that, similar to immature embryos, the callus induction frequency of inflorescences with the size about $6 \mathrm{~mm}$ were $100 \%$, but the regeneration frequency of the induced callus differed significantly at the level of $P<0.05$ (data not shown). In 50 surveyed cultivars, 34 cultivars had the frequency less than $60 \%$, accountting for $68 \%$, and the lowest one was Liao0801 $(25.3 \%), 11$ cultivars had the frequencies from 40 to $90 \%$, accounting for $22 \%$, and five cultivars had the frequencies more than $90 \%$, accounting for $10 \%$. Among them, the top two cultivars were Liao0802 and Wennong18 with the equal regeneration frequency of $97.3 \%$. After vernalization, the regenerated plantlets were transferred to the growth room, and 40 out the 50 surveyed cultivars obtained the matured seeds, while 10 cultivars had some plants with no pollen which cannot get seeds, and Shannong044 was the cultivar with the lowest ratio $(94.3 \%)$ of the fertile plants (Table 1). Same with the plantlets regenerated from callus of immature embryos, the plantlets regenerated from the callus of young spikes which cannot get the mature seeds were mainly the dwarf mutants with no pollen. No obvious agronomic trait change was observed in fertile plantlets.

\section{The tissue culture capacity of isolated anthers}

100 anthers of each replicate were inoculated on the induction medium, three weeks later the embryonic callus were observed with naked eyes, and they were transferred to the regeneration medium when the callus grew to $1 \mathrm{~mm}$. The regenerated plantlets appeared in three weeks (Figure 3A). The results show that the embryonic callus can be obtained in all the cultivars, but differed from immature embryos and inflorescences, the induction frequency of those from different cultivars were significantly different, while the regeneration of green plantlets were also significantly different. The induction frequencies were less than $25 \%$ in 33 cultivars, accounting for $66 \%, 14$ cultivars had the frequencies from 25 to $60 \%$, accounting for $25 \%$. While Ji8802, Weimai7 and K35 were the top three with induction frequencies more than $75 \%$. However, the albinos regenerated from induced callus were unable to survive (Figure 3B). As shown in Table 1, the regeneration frequencies of green plantlets varied in a large spectrum, ranging from 42.5 to $88.5 \%$. Among them, K35 had the highest callus induction efficiency, but its regeneration frequency of green plantlets was 

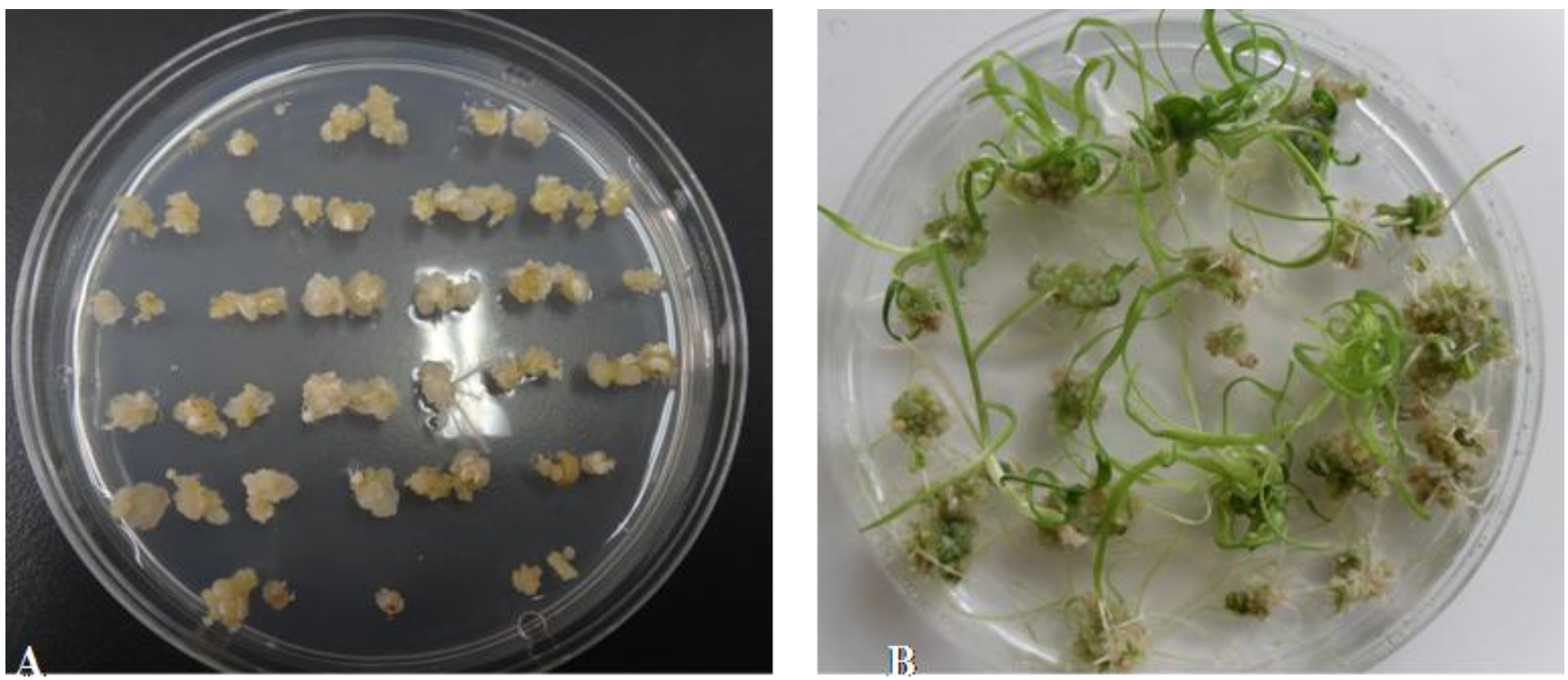

Figure 2. Callus formation and regeneration of the inflorescences. A. The callus formation after three weeks induction. B. The regeneration of the induced callus from inflorescences.
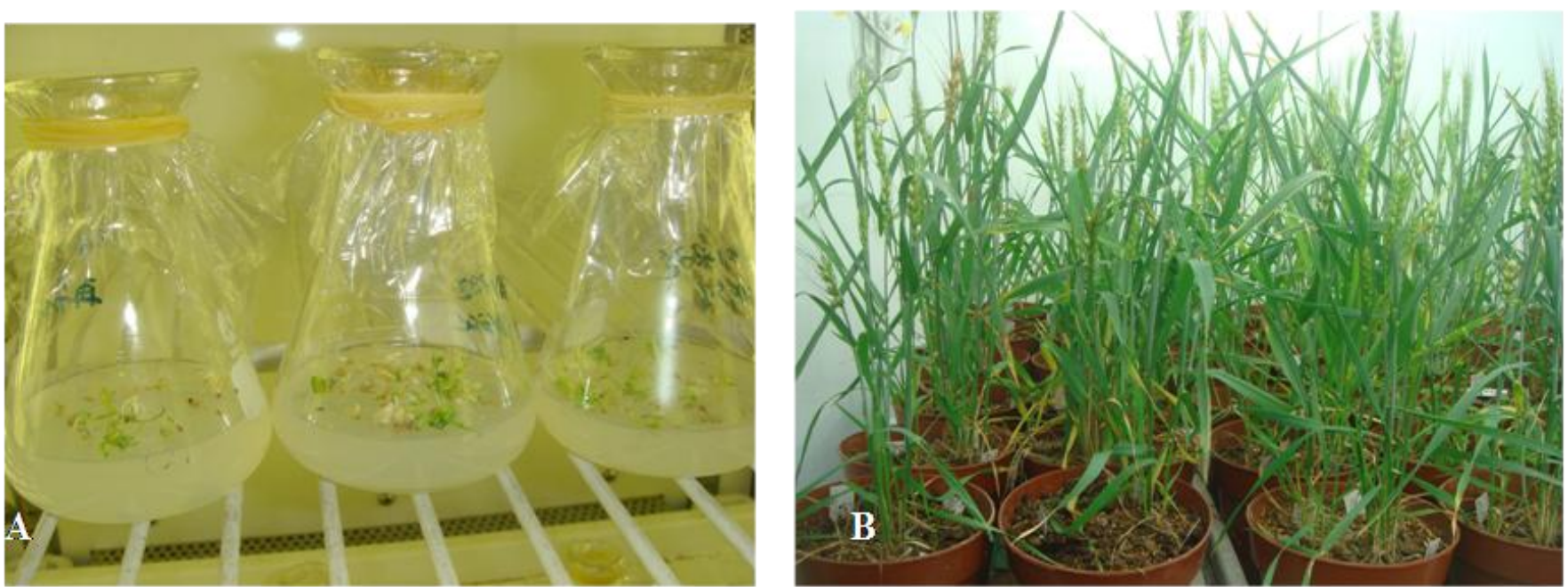

Figure 3. Regeneration of the callus induced from isolated anthers and the agronomic performance of the regenerated plants. A. The regeneration of the induced callus from isolated anthers. B. The agronomic performance of the regenerated plants in growth room.

lower than Ji8802, leading to an inferior final anther culture capacity to Ji8802. Consequently, the tissue culture capacity of anther was co-determined by both the efficiency of callus induction and the regeneration frequency of green plantlets. The regenerated green plantlets were transferred to the compost and grew to three tillers. After the chromosome number checking and the doubling treatment of the haploids, the plantlets were transferred to vernalization to grow in growth room. As shown in Table 1, the ratios of the fertile plantlets (FFAN) surveyed 50 cultivars ranging from $83.3 \%$ (Linmai No.6) to $98.7 \%$ (990512). The failure of chromosome doubling was the main reason that resulted to no seed. Some dwarf mutants were also observed in some cultivars (data not shown).

\section{The correlations of the tissue culture capacities of different explants}

The correlations of tissue culture capacities among inflorescences, immature embryos and isolated anthers were analyzed, and the results indicate that the capacities of tissue culture from immature embryos and 
Table 2. Correlations of different factors involved in tissue culture capacity.

\begin{tabular}{lccccc}
\hline Parameter & RFYS & RFIM & FCINAN & FRGP & ANCP \\
\hline RFYS & 1 & & & & \\
RFIM & 0.93 & 1 & & & \\
FCIAN & 0.017 & -0.004 & 1 & & \\
FRGP & -0.26 & -0.26 & 0.28 & 1 & \\
ANCP & -0.04 & -0.057 & 0.96 & 0.40 & 1 \\
\hline
\end{tabular}

FRYS, Frequency of inflorescences regeneration; FRIM, frequency of immature embryos regeneration; FCINAN, callus induction frequency from isolated anthers; NRGP, numbers of regenerated green plantlets; FRGP, frequency of regenerated green plantlets; ANCP, anther culture capacity.

inflorescences were highly correlated $(r=0.92, P<0.01)$. However, both of them have low correlations with anther culture capacity (Table 2), indicating that we can predict tissue culture capacity of immature embryos with that of inflorescences; but it makes no sense for anther culture capacity. The anther culture capacity was highly correlated with the callus induction frequency $(r=0.96$ $P<0.01$ ), and comparatively lower correlated with the frequency of regenerated green plantlets $(r=0.40$, $P<0.01$ ), while the coefficient between the frequency of regenerated green plantlets and that of induced callus from isolated anthers was $0.28(P<0.01)$. Accordingly, the anther culture capacity was co-determined by callus induction frequency and green plantlets regeneration frequency, of which callus induction frequency was more important.

\section{DISCUSSION}

The present study indicates that the immature embryos with the proper size from different genetic background respond to induction medium very nicely, but the regeneration capacity of the induced callus differed greatly, so tissue culture capacities of the immature embryos were mainly determined by their regeneration frequency. The result disagrees with some previous reports which stated that the induction frequency of immature embryos was genotype dependent (Barro et al., 1999; Fennell et al., 1996; Maddock et al., 1983). This divergence maybe aroused from the size of immature embryos or the components of the induction medium used in different experiments. Previous studies also found that not all of the immature embryos with the size less than $0.5 \mathrm{~mm}$ or more than $1.5 \mathrm{~mm}$ can be induced into callus and the best response was within the size around $1 \mathrm{~mm}$ (Sharma et al., 1982). In the present study, the size of immature embryos were selected strictly in $1 \pm$ $0.1 \mathrm{~mm}$, and the $\mathrm{SD}_{2}$ induction medium used herein was proved to be a quite good medium for callus induction. All were induced into callus which indicated that the callus induction of immature embryos was genotypesindependent and the regeneration efficiency of the induced callus can represent the tissue culture capacity of immature embryos.

Genotype independent of callus induction frequency from inflorescences was also in disagreement with some previous studies (Maddock et al., 1983; Sharma et al., 1995), but consistent with the report of Redway et al. (1990). The difference may also be related to the medium used and the development stage of the inflorescences. Medium composition, callus age and vernalization period of donor plants were the main factors reported, which had great effects on inflorescences regeneration capacity (Kavas et al., 2008; Maddock et al., 1983; Pellegrineschi et al., 2003). Our preliminary studies indicate that the inflorescences which have yellowish transparent color with the length less than $2 \mathrm{~mm}$ cannot be induced into callus at all, and those with the sizes from 3 to $5 \mathrm{~mm}$ responded to induction medium, but not all of them can develop into callus, whereas those with the sizes from 5 to $8 \mathrm{~mm}$ can be initiated into callus easily. Based on these preliminary experiments, only the inflorescences with the sizes from 5 to $7 \mathrm{~mm}$ were used for callus induction in the present study, and the results indicate that the callus induction of inflorescences in this specific development stage were genotype independent. W4 medium was first used herein for inflorescences callus induction and the high efficiency callus induction ability indicated that $\mathrm{W} 4$ is a vigorous medium for inflorescences callus induction. Therefore, apart from the induction medium and other effectors, the tissue culture capacity of inflorescences was mainly determined by regeneration frequency of the induced callus.

In the present study, Ji8802, Weimai7 and K35 were the top three cultivars with outstanding anther culture capacity. Among them, Ji8802 has strong winter wheat growth habit which need at least 40 days vernalization at $4^{\circ} \mathrm{C}$ and Weimai 7 is also a winter wheat cultivar that need about 30 days vernalization at $4^{\circ} \mathrm{C}$. This characteristic made them very sensitive to the vernalization conditions, such as the lasting time and temperature. On the other hand, for Weimai7, the spikes often break through the cover leaf and expose to the open air when its microspores develop to the mid- to late-uninucleate stage, that lead to the isolated anthers which are always 
spoiled by contaminations. Compared with Ji8802 and Weimai7, K35 is a cultivar not sensitive to vernalization and photoperiod, and can survive the freezing temperature of Huang-Huai wheat region in winter. Therefore, in terms of the anther culture capacity and growth habit, K35 is an optimal cultivar for anther culture.

The present study first reports the correlations of the tissue culture capacities between immature embryos, inflorescences and isolated anthers. The immature embryos were the most popular explants used in wheat genetic transformation, due to their good response to tissue culture. Inflorescences were harvested from younger plants, so it can reduce growth space and save time. According to the previous reports, physiological status of donor plants appears to have less influence on explants response in culture (Barro et al., 1999). The new finding of the close relationship between the tissue culture capacity of inflorescences and immature embryos, provided us very useful information in predicting the tissue culture capacity of different explants for a specific cultivar, reciprocally. However, anther culture capacity is mainly determined by the callus induction frequency and the ratio of the green plantlets. Some cultivars have highest callus induction frequency, but the ratio of regenerated albinos was also higher than the others. The final capacity of this sort of cultivars was not the highest, while some cultivars with average callus induction frequency and lower ratio of regenerated albinos sometimes had excellent anther culture capacity. So far the mechanism involved in the formation of albinos was veiled, and there is need for more works to be focused on how to decrease the ratio of albinos during the wheat anther culture.

\section{ACKNOWLEDGEMENTS}

This research was supported by the National Transgenic Major Project (2012ZX08002-004), Shandong Agriculture and Seed Industry (2012), China Agriculture Research System (CARS-03-1-08), Shandong Agriculture Research System, and Outstanding Agricultural Talent and Team.

\section{REFERENCES}

Barro F, Martin A, Lazzeri PA, Barceló P (1999). Medium optimization for efficient somatic embryogenesis and plant regeneration from immature inflorescences and immature scutella of elite cultivars of wheat barley and tritordeum. Euphytica 108:161-167

Bhalla PL (2006). Genetic engineering of wheat - current challenges and opportunities. Trends Biotechnol. 24(7):305-311.

Caswell K, Leung N, Chibbar RN (2000). An efficient method for in vitro regeneration from immature inflorescence explants of Canadian wheat cultivars. Plant Cell Tiss. Organ Cult. 60:69-73

Cheng M, Fry JE, Pang SZ, Zhou HP, Hironaka CM, Duncan DR, Conner TW, WanYC (1997). Genetic transformation of wheat mediated by Agrobacterium tumefaciens. Plant Physiol. 115:971-980

Ding LP, Li SC, Gao JM, Wang YS, Yang GX, He GY (2009). Optimization of Agrobacterium-mediated transformation conditions in mature embryos of elite wheat. Mol. Biol. Rep. 36:29-36.

Fennell S, Bohorova N, Van Ginkel M, Crossa J, Hoisington D (1996). Plant regeneration from immature embryos of 48 elite CIMMYT bread wheats. Theor. Appl. Genet. 92:163-169

Haliloglu K (2006). Efficient regeneration system from wheat leaf base segments. Biol. Plant. 50:326-330

He ZH, Rajaram S, Xin ZY, Huang GZ (2001). A history of wheat breeding in China. Mexico, DF CIMMYT pp.1-94.

Hu T, Metz S, Chay C, Zhou HP, Biest N, Chen G, Cheng M, Feng X, Radionenko M, Lu F, Fry J (2003). Agrobacterium-mediated largescale transformation of wheat Triticum aestivum $\mathrm{L}$ using glyphosate selection. Plant Cell Rep. 21:1010-1019.

Kavas M, Öktem HA, Yücel M (2008). Factors affecting plant regeneration from immature inflorescences of two winter wheat cultivars. Biol. Plant. 52(4):621-626.

Liu W, Zheng M, Polle E, Konzak CF (2002). Highly efficient doubledhaploid production in wheat Triticum aestivum $\mathrm{L}$ via induced microspore embryogenesis. Crop Sci. 42:686-692.

Maddock SE, Lancaster VA, Risiott R, Franklin J (1983). Plant regeneration from cultured immature embryos and inflorescences of 25 cultivars of wheat Triticum aestivum . J. Exp. Bot. 34:915-926.

Mejza SJ, Morgant V, Di Bona DE, Wong JR (1993). Plant regeneration from isolated microspores of Triticum aestivum. Plant Cell Rep. 12:149-153.

Murashige T, Skoog F (1962). A revised medium for rapid growth and bioassays with tobacco tissue cultures. Physiol. Plant. 5:473-479.

Özgen M, Türet M, Altmok S, Sancak C (1998). Efficient callus culture induction and plant regeneration from mature embryo culture of winter wheat Triticum aestivum L genotypes. Plant Cell Rep. 18:331335.

Özgen M, Türet M, Avcı M (2001). Cytoplasmic effects on the tissue culture response of callus from winter wheat mature embryos. Plant Cell Tiss. Organ Cult. 64:81-84.

Patnaik D, Vishnudasan D, Khurana P (2006). Agrobacterium-mediated transformation of mature embryos of Triticum aestivum and Triticum durum. Curr. Sci. 91(3):307-319.

Pellegrineschi A, Brito RM, McLean S, Hoisington D, Przetakiewicz A, Orczyk W, Nadolska-Orczyk A (2003). The effect of auxin on plant regeneration of wheat barley and triticale. Plant Cell Tiss. Organ Cult. 73:245-256.

Pellegrineshi A, Noguera LM, Skovmand B, Brito RM, Velazquez L, Salgado MM, Hernandez R, Warburton M, Hoisington D (2002). Identification of highly transformable wheat genotypes for mass production of fertile transgenic plants. Genome 45:421-430.

Raziuddin J, Bakht Swati ZA, Shafi M, Farhat U, Akmal M (2010). Effect of cultivars and culture medium on callus formation and plant regeneration from mature embryos of wheat Triticum aestivum $\mathrm{L}$. Pak. J. Bot. 42(1):639-652.

Redway FA, Vasil V, Lu D, Vasil IK (1990). Identification of callus types for long-term maintenance and regeneration from commercial cultivars of wheat Triticum aestivum L . Theor. appl. Genet. 79:609617.

Risacher T, Craze M, Bowden S, Paul W, Barsby T (2009). Highly efficient Agrobacterium-mediated transformation of wheat via in planta inoculation. Methods Mol. Biol. 478:115-124.

Sharma HC, Gill BS (1982). Effect of embryo age and culture media on plant growth and vernalization response in winter wheat. Euphytica 31:629-634.

Sharma VK, Rao A, Varshney A, Kothari SL(1995). Comparison of developmental stages of inflorescence for high frequency plant regeneration in Triticum aestivum $\mathrm{L}$ and $T$. durum Desf. Plant Cell Rep. 15:227-231.

Sood S, Dhawan R, Sigh K, Bains NS (2003). Developmental of novel chromosome doubling strategies for wheat $\times$ maize system of wheat haploid production. Plant breed. 122:493-496.

Viertel K, Hess D (1996). Shoot tips of wheat as an alternative source for regenerable embryogenic callus cultures. Plant Cell Tiss. Organ Cult. 44:183-188.

Wang CT, Wei ZM (2004). Embryogenesis and regeneration of green plantlets from wheat Triticum aestivum leaf base. Plant Cell Tiss. Organ Cult. 77:149-156.

Wang YL, Xu MX, Yin GX, Tao LL, Wang DW, Ye XG (2009). Transgenic 
wheat plants derived from Agrobacterium-mediated transformation of mature embryo tissues. Cereal Res. Commun. 37:11-12.

Wu H, Doherty A, Jones HD (2009). Agrobacterium-mediated transformation of bread and durum wheat using freshly isolated immature embryos. Methods Mol. Biol. 478:93-103.

Ye XG, Wang YL, Kang L, Du LP, Xu HJ (2005). Screening of wheat genotypes sensitive to Agrobacterium tumefaciens infection and transformation. Acta agron. Sin. 31(12):1552-1556. In Chinese with English abstract

Zale JM, Borchardt-Wier H, Kidwell KK, Steber CM (2004). Callus induction and plant regeneration from mature embryos of a diverse set of wheat genotypes. Plant Cell Tiss. Organ Cult. 76:277-281.

Zhang B, Jia D, Zhang YP, Gao ZQ, Ma JJ (2009). A preliminary study of regeneration system of winter wheat immature embryo and its Agrobacterium transformation. Chin. Agric. Sci. Bull. 25(10):68-71. In Chinese with English abstract
Zhang B, Zhao M, Gao ZQ, Ding ZS, Shi YL, Fang LF (2007). Optimizing transformation systems of spring wheat mediated via Agrobacterium tumefaciens. J. Nuc. Agric. Sci. 21(2):124-127. In Chinese with English abstract

Zhuang QS (2003). Chinese wheat improvement and pedigree analysis. Chinese Agriculture Press Beijing pp. 1-681. 